JURNAL RISET REKAYASA ELEKTRO

Vol.3, No.1, Juni 2021, Hal. 35 46

P-ISSN: 2685 - $4341 \quad$ E-ISSN: 2685 - 5313

\title{
Perancangan Kebutuhan Daya dan Instalasi Listrik Pada Gedung Askrindo Bogor
}

\author{
Ramadan Carles $\mathbf{A}^{\mathbf{1}}$, Winarso ${ }^{2}$ \\ Program Studi S1 Teknik Elektro, Universitas Muhammadiyah Purwokerto \\ Fakultas Teknik dan Sains, Universitas Muhammadiyah Purwokerto
}

\section{Informasi Makalah}

Dikirim, 26 Januari 2020

Direvisi, 20 Maret 2021

Diterima, 21 April 2021

\section{Kata Kunci: \\ Perencanaan \\ Pencahayaan \\ Dialux \\ Kebutuhan Daya \\ Drop Voltage \\ Etap}

\section{INTISARI}

Dalam pembangunan sebuah gedung diperlukan perancangan instalasi listrik dan sistem pencahayaan yang matang agar mendapatkan hasil yang maksimal. Perencanaan instalasi listrik dibuat berdasarkan gambar perencanaan konstruksi dan arsitektur gedung dengan software autocad dan perencanaan konsumsi daya listrik gedung menggunkan software ETAP. Perancangan sistem kuat pencahayaan (lux) pada Gedung Askrindo Bogor dibuat berdasarkan standar kuat pencahayaan SNI yaitu dengan perhitungan jumlah armatur lampu dan disimulasikan menggunakan software dialux. Berdasarkan hasil perencanaan, untuk ruang lobby dengan luas $172 \mathrm{~m}^{2}$ menggunakan armatur lampu jenis recess mounted sejumlah 12 buah dengan daya lampu led 2 x 9 watt, 1800 Lumen, setelah disimulasikan dengan software dialux menghasilkan kuat pencahayaan sebesar 140 lux. Dari hasil perhitungan semua beban listrik pada gedung konsumsi daya semunya adalah 106,81 kVA, sehingga daya terpasang gedung ke PLN adalah $131 \mathrm{kVA}$. Untuk menyalurkan listrik sebesar itu pada gedung menggunakan Panel LVMDP, MDP dan SDP. Dari simulasi menggunakan software ETAP didapatkan drop tegangan pada jarak terjauh 200 meter antara panel LVMDP ke SDP adalah $4.65 \%$.Untuk melengkapi sistem distribusi daya listrik, dari hasil perhitungan rekapitulasi daya dibutuhkan kapasitor bank sebesar 30 kVAR dan Genset 250 kVA.

\section{Keyword:}

Planning

Lighting

Dialux

Power equirements

Drop Voltage

Etap

\begin{abstract}
In the construction of a building, it is necessary to design a mature electrical installation and lighting system in order to get maximum results. Electrical installation planning is made based on construction planning drawings and building architecture with Autocad software and building electrical power consumption planning using ETAP software. The design of the lighting strength (lux) system at Askrindo Bogor Building is made based on the SNI lighting strength standard, namely by calculating the number of lamp armatures and simulating it using dialux software. Based on the results of the planning, the lobby area with an area of $172 \mathrm{~m}^{2}$ uses 12 recess mounted lamp armatures with $2 \times 9$ watt LED power, 1800 lumens, after being simulated with the software, it produces a lighting strength of 140 lux. From the calculation of all electrical loads in the building, the power consumption is $106.81 \mathrm{kVA}$, so the building's installed power to PLN is $131 \mathrm{kVA}$. To distribute that much electricity to the building using the LVMDP, MDP and SDP panels. From the simulation using ETAP software, it was found that the voltage drop at the farthest distance of 200 meters between the LVMDP panel to SDP was $4.65 \%$. To complete the electrical power distribution system, from the calculation of the power recapitulation required a bank capacitor of $30 \mathrm{kVAR}$ and a generator of $250 \mathrm{kVA}$.
\end{abstract}




\section{Korespondensi Penulis:}

Ramadan Carles Andriyan

Program Studi Teknik Elektro

Fakultas Teknik dan Sains Universitas Muhammadiyah Purwokerto

JL. Raya Dukuhwaluh, Purwokerto, 53182

Email: ramadancrls999@gmail.com

\section{PENDAHULUAN}

Pada masa sekarang ini kebutuhan energi listrik boleh dikatakan kebutuhan yang menduduki peringkat teratas bahkan telah menjadi barometer maju tidaknya suatu daerah. Dengan adanya energi listrik kita dapat memfungsikan segala macam alat-alat elektronik dan berbagai macam peralatan modern di masa sekarang ini. Bahkan kebutuhan energy listrik juga di gunakan berbagai macam proyek pembangunan, perkantoran, perindustrian dan sector-sektor lainnya.

Instalasi tenaga listrik merupakan salah satu bagian yang sangat penting dalam pembangunan gedung atau bangunan untuk melindungi keselamatan manusia dan hewan yang berada di daerah sekitar sehingga aman dari sengatan listrik. Mengingat masih sering terjadinya kebakaran pada suatu bangunan baik rumah, pasar maupun gedung - gedung yang penyebabnya diduga karena hubung singkat atau secara umum karena listrik dan masih banyak ditemukan instalasi listrik pada rumah ataupun bangunan yang mengabaikan persyaratan umum instalasi listrik (PUIL), Standar Nasional Indonesia (SNI) dan tidak memperhatikan ketentuan dari keamanaan dan teknologi modern dan juga estetika keindahan. [1]

Tenaga listrik adalah hal utama yang diperlukan dalam industri jasa seperti hotel, perkantoran dan instansi lainnya karena banyak peralatan yang beroperasi dengan tenaga listrik. Listrik sangat penting dalam setiap kehidupan manusia, tetapi juga dapat menimbulkan bahaya jika terjadi kecelakaan. Oleh karena itu dalam merancang instalsi listrik untuk gedung juga memerlukan perencanaan khusus.[2]

Di dalam pemasangan instalasi listrik pada suatu gedung perlu di perhatikan berbagai hal seperti kekurangan daya, kepincangan daya, ganguan instalasi dan berbagai gangguan lainnya. Agar instalasi listrik yang terpasang pada gedung tersebut tidak terjadi berbagai kendala. [2]

Pada skripsi ini penulis bermaksud untuk merancang kebutuhan daya dam instalasi listrik pada Gedung Askrindo Bogor sesuai dengan standar kelistrikan dan simulasi aliran daya menggunakan Etap.

\section{METODE PENELITIAN}

\subsection{Diagram Alir}

Perancangan beban penerangan, stop kontak dan AC digunakan untuk menentukan kebutuhan daya terpasang, hasil tersebut digunakan untuk menentukan ukuran kabel, gawai proteksi dan keseimbangan beban setiap panel lalu menentukan kebutuhan kapasitor bank, kapasitas transformator dan kapasitas genset. Alur penelitihan lebih jelas terlihat pada Gambar 1 : 


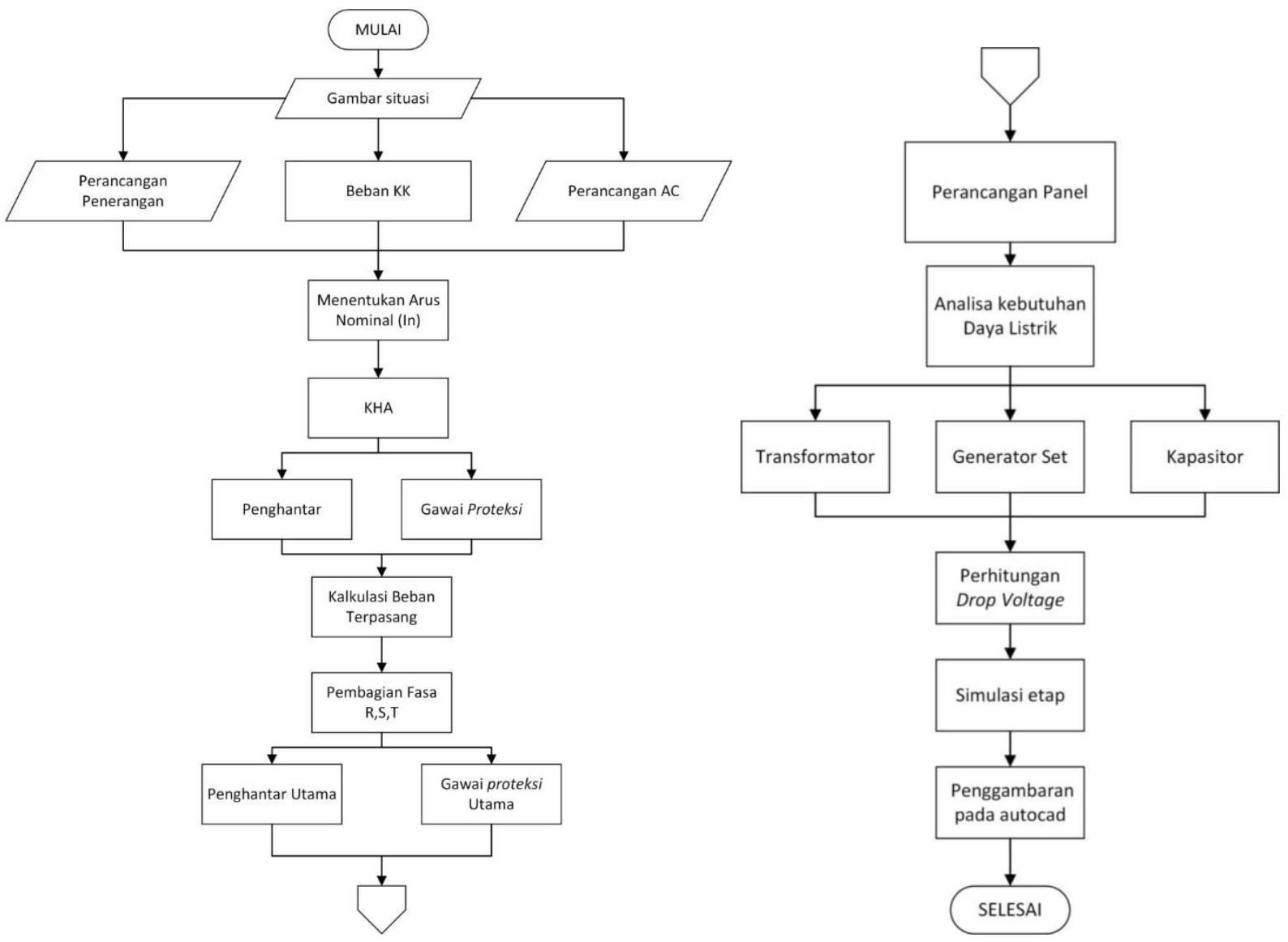

Gambar 1. Diagram alir

\subsection{Perancangan Penerangan}

a. Menghitung armature lampu: [3]

$\mathrm{N}=\frac{\mathrm{E} \times \mathrm{A}}{\mathrm{n} \times \phi \times \mathrm{kp} \times \mathrm{kd}}$

Keterangan:

$\mathrm{N}=$ Jumlah titik lampu

$\mathrm{E}=$ Kuat penerangan (Lux)

$\mathrm{A}=$ Luas permukaan $\left(\right.$ Meter $\left.^{2}\right)$

$\phi \quad=$ Total nilai pencahayaan (LUMEN)

$\mathrm{kd}=$ factor depresiasi 0,8

$\mathrm{kp}=$ factor utility 0,5

$\mathrm{n} \quad=$ Jumlah Lampu dalam 1 titik

b. Menghitung Kepadatan Daya [4]:

$\mathrm{Pa}=\frac{W \text { total }}{A}\left(\mathrm{watt} / \mathrm{m}^{2}\right)$

Keterangan:

$\mathrm{Pa}=$ Kepadatan Daya

$\mathrm{W}=$ Kebutuhan daya semua armature

$\mathrm{A}=$ Luas bidang kerja

c. Simulasi

Melakukan simulasi intensitas pencahayaan (Lux) ruangan 3d yang berdasarkan gambar situasi, spesifikasi lampu serta jumlah armature hasil perhitungan menggunakan software dialux. 


\subsection{Perancangan AC dan Fan}

a. Perancangan kebutuhan AC [5]

Kebutuhan $\mathrm{AC}=\frac{\mathrm{p} \times \mathrm{l} \times \mathrm{t}}{3} \times 500 \mathrm{BTU}$

Keterangan :

Kapasitas AC berdasarkan PK:

$1 / 2 \mathrm{PK}=5000 \mathrm{Btu} / \mathrm{h}$ (ukuran ruangan $10 \mathrm{~m}^{2}$ )

$3 / 4 \mathrm{PK}=7000 \mathrm{Btu} / \mathrm{h}$ (ukuran ruangan $14 \mathrm{~m}^{2}$ )

$1 \mathrm{PK}=9000 \mathrm{Btu} / \mathrm{h}$ (ukuran ruangan $18 \mathrm{~m}^{2}$ )

$1 \frac{1}{2} \mathrm{PK}=12000 \mathrm{Btu} / \mathrm{h}$ (ukuran ruangan $24 \mathrm{~m}^{2}$ )

$2 \mathrm{PK}=18000 \mathrm{Btu} / \mathrm{h}$ (ukuran ruangan $36 \mathrm{~m}^{2}$ )

b. Perancangan Fan

$\mathrm{CMH}$ : volume ruang $\mathrm{x} \mathrm{ACH}$

Keterangan:

$\mathrm{CMH}$ : Cubic Meter Hour atau kebutuhan sirkulasi udara di dalam ruang

$\mathrm{ACH}$ : Air Changer Per Hour (Pergantian udara per jam)

\subsection{Kuat Hantar Arus}

Untuk sistem 1 fasa :

In $=\frac{\mathrm{P}}{\mathrm{V} x \cos \phi}($ ampere $)$

Untuk sistem 3 fasa :

In $=\frac{P}{\sqrt{3} \times V \times \cos \phi}($ ampere $)$

$\mathrm{KHA}=125 \% \times \mathrm{In}$

\subsection{Drop Voltage}

a. Perhitungan

Berikut adalah rumus menghitung drop voltage [3]

$\mathrm{R}=\frac{\rho \times \ell}{\mathrm{A}}$

$\Delta \mathrm{V}=\mathrm{I} \times \mathrm{R}$

Keterangan :

$\Delta \mathrm{V}=$ drop voltage (volt)

I = arus nominal (ampere)

$\boldsymbol{\rho}=$ tahanan jenis $(\Omega \mathrm{m})$

$\ell=$ panjang penampang $(\mathrm{m})$

$\mathrm{A}=$ luas penampang penghantar $\left(\mathrm{m}^{2}\right)$

$\mathrm{R}=\operatorname{tahanan}(\mathrm{Ohm})$

b. Simulasi

Drop voltage disimulasikan menggunakan software etap untuk mendapatkan tegangan jatuh berdasarkan jarak, spesifikasi penghantar serta daya terpasang.

2.6. Analisa Beban Terpasang

Berikut adalah rumus menentukan daya maksimum [6]:

Daya maksimum $=\frac{\text { Beban terpasang }(\text { Watt }) \times \text { faktor kebutuhan }}{\frac{1}{\text { Faktor Kebersamaan }}}$

\subsection{Perancangan Kapasitor Bank}

Berikut adalah langkah menentukan kapasitor bank [7]

a. Menentukan total kebutuhan daya aktif (P)

b. Menentukan Cos $\phi$ sebelum perbaikan 
c. Menentukan nilai Cos $\phi$ yang ingin dicapai

d. Menentukan daya reaktif $(\mathrm{Q})$ sebelum perbaikan

$\mathrm{Q} 1=\mathrm{P} \times \tan \phi 1$ (VAR)

e. Menentukan daya reaktif $(\mathrm{Q})$ setelah perbaikan

$\mathrm{Q} 2=\mathrm{P} \times \tan \phi 2(\mathrm{VAR})$

f. Daya reaktif koreksi

$\mathrm{Qc}=\mathrm{Q} 1-\mathrm{Q} 2$ (VAR)

\section{HASIL DAN PEMBAHASAN}

\subsection{Perancangan Penerangan}

a. Perhitungan titik lampu

Perhitungan titik lampu bertujuan untuk menentukan nilai daya pencahayaan terpasang. Perhitungan titik lampu ditentukan berdasasrkan lstandar lux ruangan, luas ruangan serta lumen lampu yang digunakan, maka sebagai sample berikut adalah rumus menghitung titik lampu pada Ruang arsip dan mushola :

$$
\begin{aligned}
\mathrm{N} & =\frac{E \times A}{n \times \phi \times k p \times k d} \\
& =\frac{300 \times 475}{2 \times 3600 \times 0,5 \times 0,8} \\
& =49,48 \text { titik }
\end{aligned}
$$

Dengan memperhitungan pembulatan dan kerapihan plafon, maka jumlah armature yang dipasang adalah 48 titik. Maka setelah itu dapat dihitung nilai kepadatan daya pencahayaan sebagai berikut :

$\mathrm{Pa}=\frac{\text { Watt total }}{A}=\frac{36 \times 48}{475}=3,64 \mathrm{watt} / \mathrm{m}^{2}$

Nilai kepadatan daya pencahayaan adalah 3,36 watt $/ \mathrm{m}^{2}$ yang masih memenuhi standar batas kepadatan daya pencahayaan kantor yaitu $15 \mathrm{wat} / \mathrm{m}^{2}$.

Berdasarkan perhitungan titik lampu, maka didapatkan hasil kebutuhan titik lampu untuk lantai 1 adalah 210 titik dengan daya terpasang 5946 watt, kebutuhan titik lampu lantai 2 adalah 179 titik dengan daya terpasang 4944 watt dan kebutuhan lampu lantai 3 adalah 10 titik dengan daya terpasang 304 watt

b. Simulasi

Simulasi pencahayaan dilakukan menggunakan software dialux berdasarkan hasil perhitungan titik armature lampusp, esifikasi lampu serta gambar situasi ruangan maka didapatkan hasil simulasi gambar 3D dan lux yang dihasilkan pada ruangan tersebut, sebagai sample berikut adalah hasil simulasi pencahayaan ruang arsip dan mushola lantai 1:

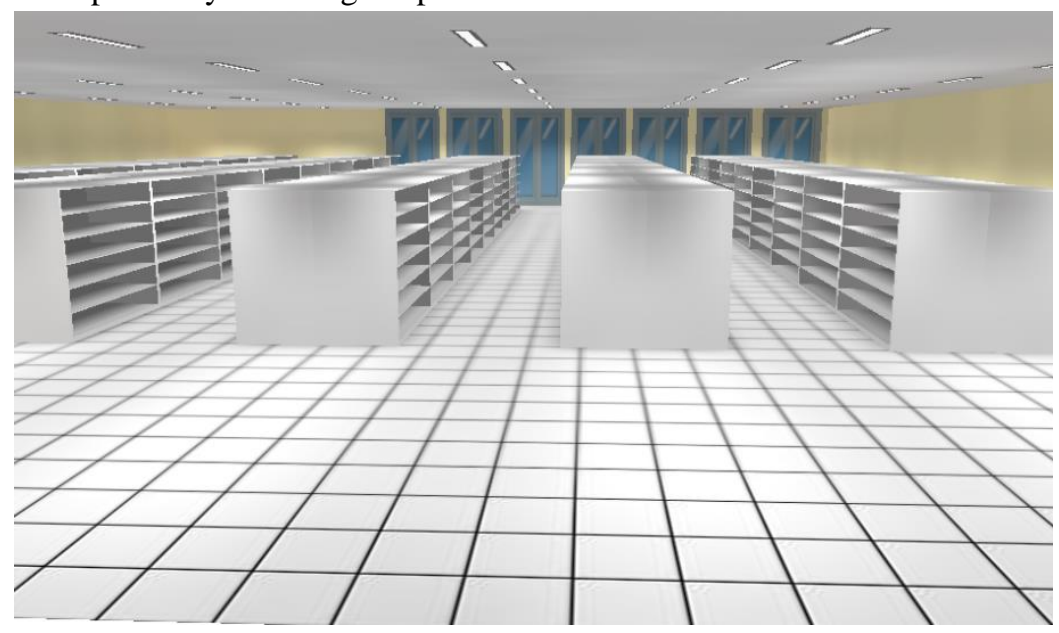

Gambar 3. Visualisasi 3D ruang arsip 


\begin{tabular}{|c|c|c|c|c|c|}
\hline \multicolumn{4}{|c|}{$\begin{array}{l}\text { Height of Room: } 2.800 \text { m, Mounting Height: } 2.864 \text { m, Light loss factor: } \\
0.80\end{array}$} & \multicolumn{2}{|c|}{ Values in Lux, Scale 1:321 } \\
\hline Surface & $\rho[\%]$ & $E_{a v}[\mid x]$ & $E_{\min }[\mid x]$ & $E_{\text {max }}[\mid x]$ & uo \\
\hline Workplane & 1 & 113 & 4.29 & 304 & 0.038 \\
\hline Floor & 20 & 97 & 4.01 & 247 & 0.041 \\
\hline Ceiling & 70 & 32 & 7.99 & 181 & 0.250 \\
\hline Walls (6) & 65 & 38 & 3.88 & 115 & 1 \\
\hline
\end{tabular}

Gambar 4. Hasil simulasi ruang arsip

Berdasarkan simulasi, tingkat pencahayaan ruang arsip yang dihasilkan adalah 304 lux, hasil tersebut sudah sesuai dengan perencanaan awal lux standar yang ingin dicapai yaitu 300 lux.

\subsection{Perancangan AC dan Fan}

a. Perancangan AC

Digunakan 2 jenis AC pada rancangan ini yaitu split wall mount untuk ruangan ukuran sedang dan ceiling mounted 3 phase untuk ruangan dengan ukuran besar. Berikut adalah sample perhihtungan kebutuhan AC untuk ruang lobby lantai 1 dengan luas $175 \mathrm{~m}^{2}$ :

$$
\begin{aligned}
\mathrm{AC} & =\frac{\mathrm{p} \times \mathrm{l} \times \mathrm{t}}{3} \times 500 \\
& =\frac{172 \times 2,8}{3} \times 500 \\
& =80267 \mathrm{BTU}
\end{aligned}
$$

Kebutuhan AC untuk ruang lobby adalah 80.260 BTU sehingga kapasitas AC yang terpasang harus lebih besar atau sama dengan hasil rumus kebutuhan AC sesuai dengan spesifikasi AC yang dijual dipasaran.

Berdasarkan Perhitungan AC, maka didapatakan total kebutuhan AC pada lantai 1 adalah 435400 BTU dengan daya terpasang adalah 36790 Watt dan kebutuhan AC pada lantai 2 adalah 412533 BTU dengan daya terpasang adalah 38300 watt

b. Perancangan Fan

Fan dirancang untuk memperlancar sirkulasi udara pada ruangan yang membutuhkan sirkulasi udara tetapi tidak memerlukan AC. Berikut adalah sample perhitungan fan untuk ruang arsip lantai 1dengan ketentuan standar Air Changer Per Hour $(\mathrm{ACH})$ untuk ruang arsip adalah 6: $\mathrm{CMH}=\mathrm{ACH} \times$ Luas $\times$ Tinggi $=6 \times 389,5 \times 2,8=6544 \mathrm{~m}^{3} / \mathrm{jam}$

Maka kebutuhan CMH untuk ruang arsip lantai 1 adalah $6544 \mathrm{~m}^{3} / \mathrm{jam}$

Berdasarkan hasil perhitungan maka didapatkan kebutuhan fan lantai 1 adalah $7980 \mathrm{CMH}$ dengan total daya terpasang adalah 408 watt dan kebutuhan fan lantai 2 adalah $6544 \mathrm{CMH}$ dengan total daya terpasang adalah 408 watt

\subsection{Perancangan Stop Kontak}

Berdasarkan gambar situasi dan fungsi ruangan dan dengan mengasumsikan daya stop kontak adalah 110 watt maka didapatkan hasil perancangan kebutuhan stop kontak pada lantai 1 adalah 52 titik dengan total daya terpasang 5720 watt dan perancangan kebutuhan stop kontak pada lantai 2 adalah 22 titik dengan total daya terpasang 2420 watt

\subsection{Sistem Distribusi Tenaga Listrik}

Sistem pendistribusian tenaga listrik pada gedung askrindo bersumber dari transformator dengan genset sebagai daya cadangan untuk mensuply panel LVMDP, panel LVMDP terdiri dari MDP Gedung Utama, SDP Gudang, SDP Wisma dan SDP Kolam renang. Sedangkan MDP Gedung Utama terdiri dari 4 SDP, yaitu: SDP lampu dan stop kontak lantai 1, SDP lampu dan stop kontak lantai 2, SDP AC dan fan lantai 1, SDP AC dan fan lantai 2. Untuk lebih jelasnya pendistribusian tenaga listrik pada gedung askrindo terdapat pada gambar berikut : 


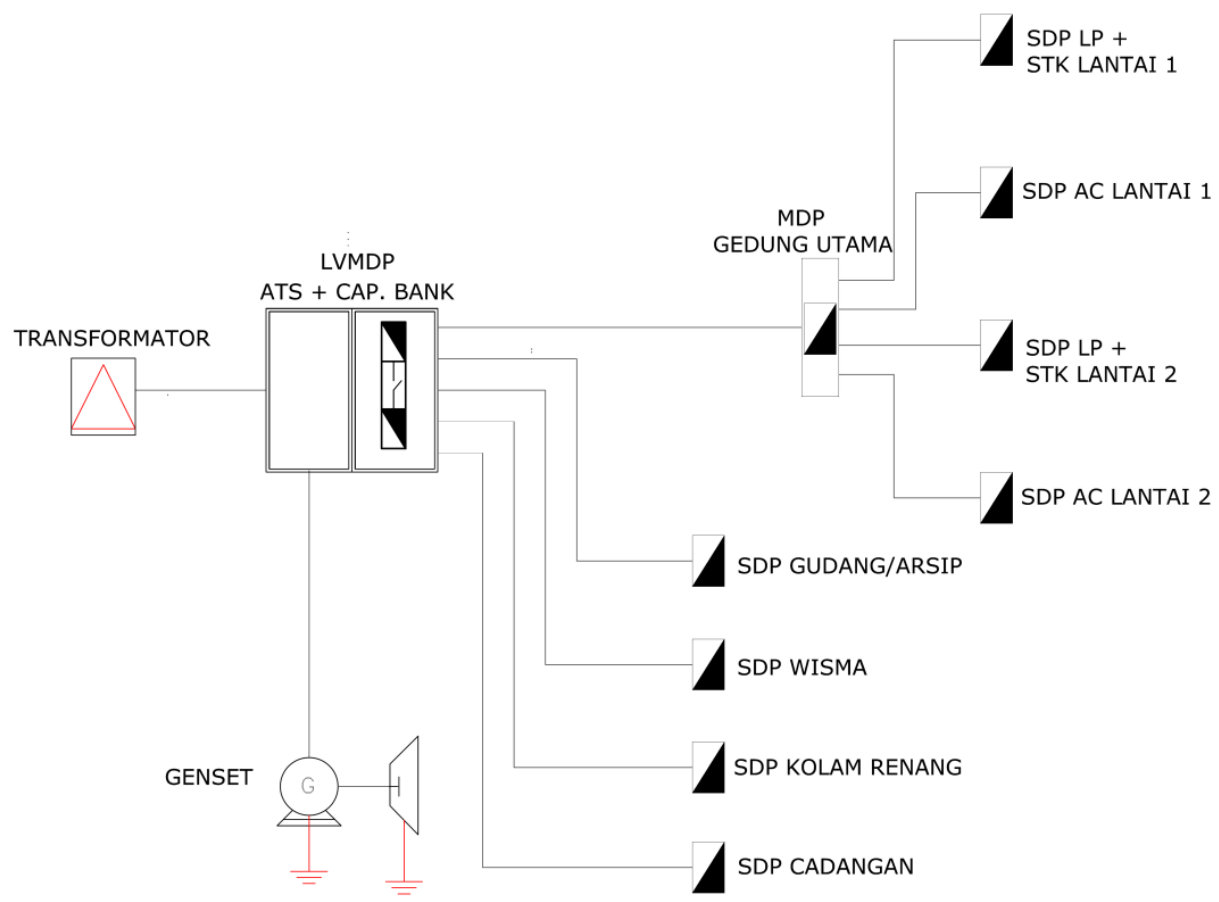

Gambar 5. Distribusi Tenaga listrik

\subsection{Analisa Kebutuhan Daya Gedung Utama}

Beban terpasang pada gedung utama meliputi beban penerangan, AC dan stop kontak dengan total beban terpasang adalah 95240 watt dengan rincian daya yang dijelaskan pada grafik berikut:

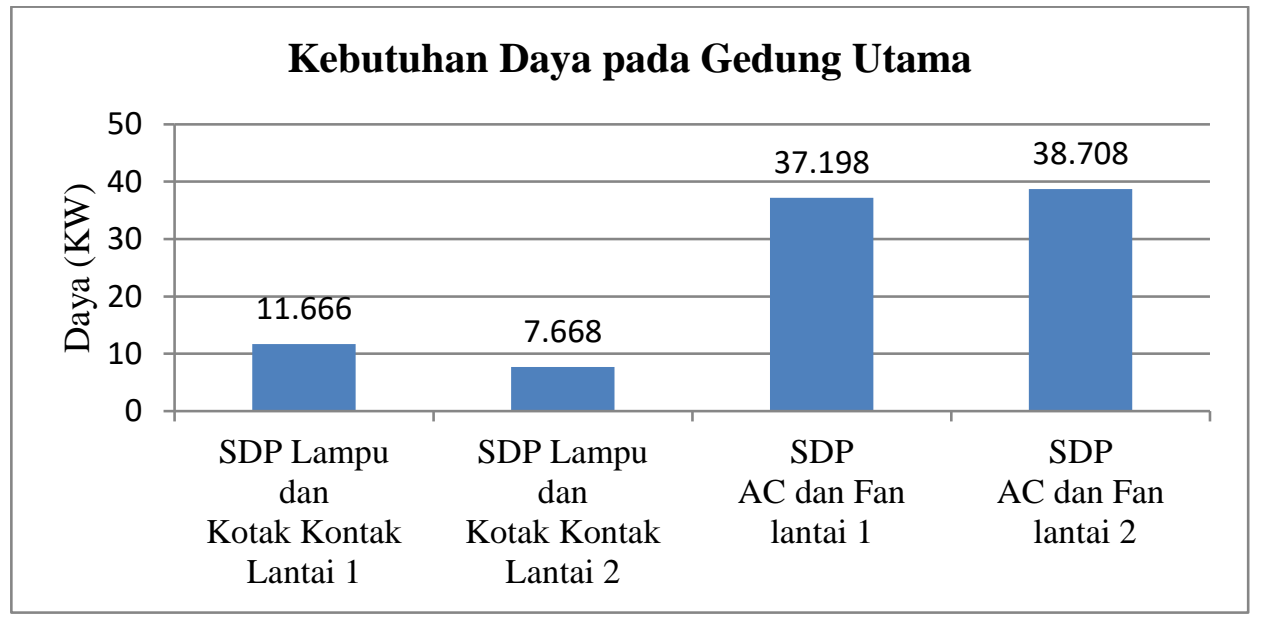

Gambar 6. Grafik kebutuhan daya pada gedung utama

Setelah diketahui daya terpasang pada gedung utama, maka dapat dianalisa kebutuhan daya maksimumnya, yaitu sebagai berikut:

Gedung Askrindo tergolong beban komersial yang memiliki factor - factor beban sebagai berikut :
1) Faktor kebutuhan
$: 90 \%$
2) Faktor diversitas (Fd)
$: 1,1$
3) Faktor beban
$: 30 \%$
4) Faktor kebersamaan $(\mathrm{Fc})$
$: 0,9$
5) $\operatorname{Cos} \phi$
$: 0,85$ 
Daya maksimum $=\frac{\text { Beban terpasang }(\text { Watt }) \times \text { faktor kebutuhan }}{\frac{1}{\mathrm{Fc}}}$

Daya maksimum $=\frac{95240 \times 90 \%}{\frac{1}{0,9}}=77924$ watt

Maka daya maksimum Gedung Utama adalah 77924 watt, angka inilah yang digunakan untuk menentukan kabel feeder dan gawai pengaman utama Gedung Utama.

\subsection{LVMDP}

Panel LVMDP terdiri dari semua beban terpasang pada gedung askrindo yaitu terdiri dari MDP Gedung Utama, SDP Gudang, SDP Wisma dan SDP Kolam renang dengan rincian ditampilkn pada tabel berikut:

Tabel 1. Data beban terpasang pada LVMDP

\begin{tabular}{ll}
\hline MDP & Total Beban (VA) \\
\hline MDP Gedung Utama & 91.675 \\
SDP Gudang & 7.700 \\
SDP Wisma & 3.500 \\
SDP Kolam Renang & 16.500 \\
Total beban terpasang & 119.375 \\
\hline
\end{tabular}

Berdasarkan tabel diatas, maka didapatkan total daya terpasang pada gedung askrindo adalah 119375 VA. Maka dapat dihitung penghantar dan gawai proteksinya, yaitu sebagai berikut:

a. Arus Nominal : $\frac{\mathrm{S}}{\sqrt{3} \times \mathrm{v}}=\frac{119573}{\sqrt{3} \times 380}=181,4 \mathrm{~A}$

b. $\mathrm{KHA}=125 \% \mathrm{x}$ In : $226,7 \mathrm{~A}$

Dengan mempertimbangan potensi perkembangan dan bertambahnya kebutuhan daya, maka kabel penghantar yang digunakan adalah NYFGbY 4 x $95 \mathrm{~mm}^{2}$ dan gawai pengaman menggunakan MCCB 200 A 4 pole.

c. Kabel Grounding

1) Jenis kabel grounding yang dipilih (sesuai PUIL 2000) adalah BCC (Bare Copper Conductor) Inti 1

2) Luas penampang (AGrounding) $=1 / 2$ AFeeder (untuk A Feeder $>35 \mathrm{~mm}^{2}$ ) Maka, AGrounding = $50 \mathrm{~mm}^{2}$

\subsection{Analisa Drop Voltage}

a. Perhitungan Drop Voltage

Jarak transformator dengan panel panel distribusi berkisar dari 11 sampai dengan 1 meter, maka dibutuhkan perhitungan drop voltage untuk mengetahui apakah drop voltage masih dibawah batas maksimal ketentuan PUIL 2010 yaitu 5\%. Sebagai sample, berikut adalah perhitungan drop voltage transformator - MDP Gedung Utama yaitu sebagai berikut:

Tegangan kerja $=380$ volt

Penghantar $=$ NYY $4 \times 70 \mathrm{~mm}^{2}$

Tahanan jenis $(\rho)=1,68 \times 10^{-8} \Omega \mathrm{m}$

Panjang penampag $(\ell)=90 \mathrm{~m}$

Luas Penampang $(A)=70 \mathrm{~mm}^{2}=70 \times 10^{-6} \mathrm{~m}^{2}$

Hambatan $(\mathrm{R})=\frac{\rho \times \ell}{\mathrm{A}}$

$$
\begin{aligned}
& =\frac{1,68 \times 10^{-8} \times 90}{70 \times 10^{-6}} \\
& =0,022 \Omega
\end{aligned}
$$


Arus bolak balik 3 fasa ( I )=139,3 A

Turun tegangan pada penghantar :

$$
\begin{aligned}
\Delta \mathrm{V} & =\mathrm{I} \times \mathrm{R} \\
& =139,3 \times 0,022 \\
& =3,01 \text { volt }
\end{aligned}
$$

Presentase turun tegangan :

$$
\begin{aligned}
(\% \Delta \mathrm{V}) & =\frac{\Delta \mathrm{V}}{\mathrm{V}} \times 100 \% \\
& =\frac{3,01}{380} \times 100 \% \\
& =0,792 \%
\end{aligned}
$$

Presentase drop voltage dari transformator ke panel MDP gedung utama adalah 0,792 \%, nilai tersebut masih dibawah batas maksimal drop voltage yang ditentukan PUIL yaitu $5 \%$.

Perbandiang panjang penghantar dengan drop voltage antara transformator dengan panel panel distribusi akan dijelaskan pada grafik berikut:

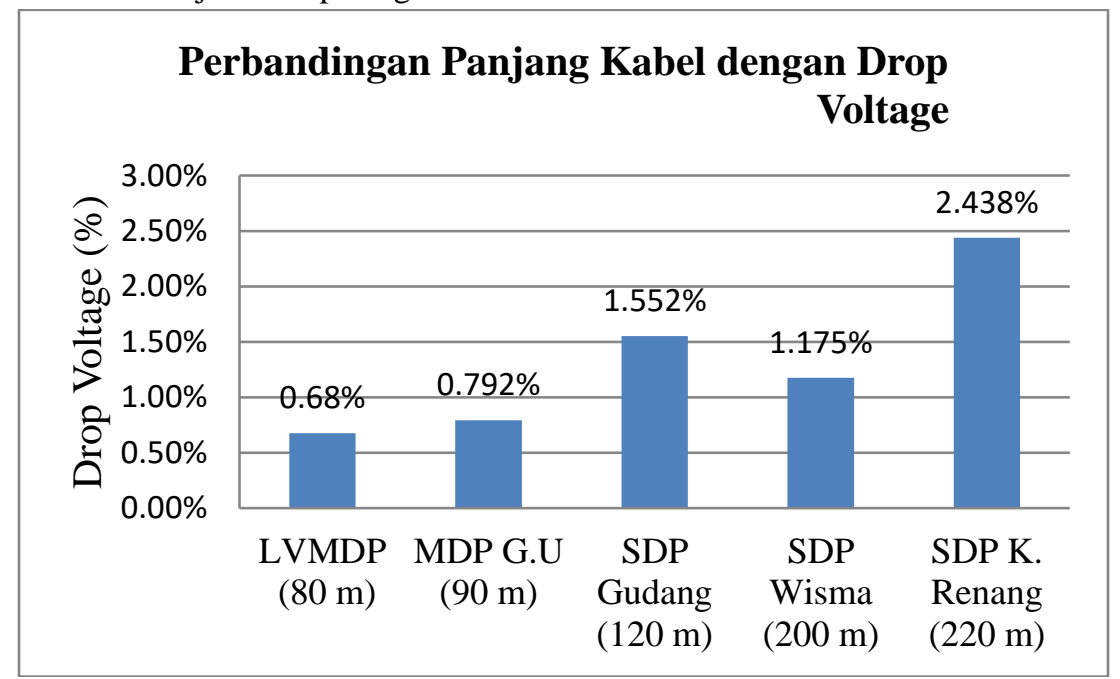

Gambar 7. Grafik perbandingan panjang kabe dengan drop voltage

b. Simulasi

Simulasi drop voltage menggunakan software etap menghasilkan load flow sebagai berikut: 


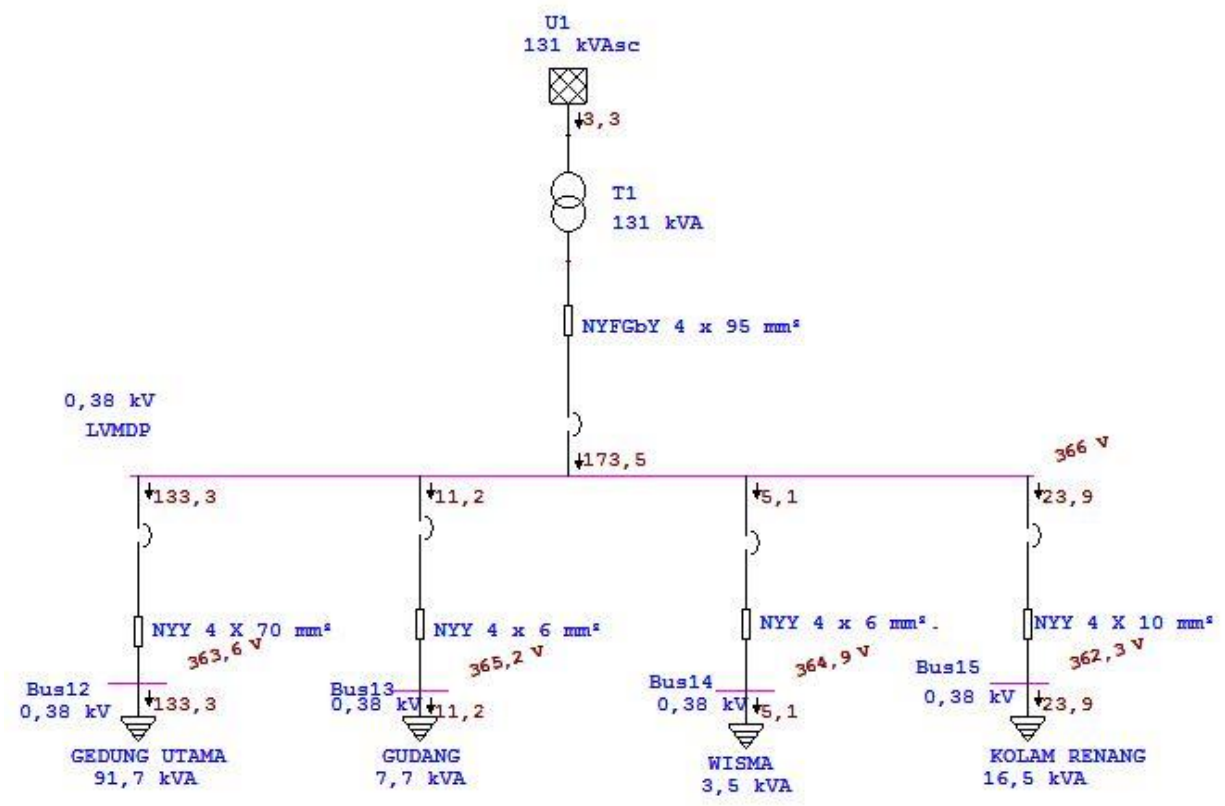

Gambar 8. Analisa drop voltage menggunakan etap

Dari hasil simulasi etap diatas dan dibandingkan dengan perhitungan, didapatkan presentasi drop voltage sebagai berikut:

Tabel 2. Drop Voltage hasil simulasi etap

\begin{tabular}{lll}
\hline \multirow{2}{*}{ Beban } & \multicolumn{2}{c}{ Drop voltage } \\
& Simulasi etap & Perhitungan \\
\hline Transformator - LVMDP & $3,6 \%$ & $0,68 \%$ \\
Transformator - MDP Gedung Utama & $4,3 \%$ & $0,792 \%$ \\
Transformator - SDP Gudang & $3,8 \%$ & $1,552 \%$ \\
Transformator - SDP Wisma & $3,9 \%$ & $1,175 \%$ \\
Transformator - SDP Kolam renang & $4,65 \%$ & $2,438 \%$ \\
\hline
\end{tabular}

Hasil simulasi etap dengan hasil perhitungan drop voltage memiliki selisih yang cukup signifikan, tetapi drop voltage hasil perhitungan maupun hasil simulasi etap masih memenuhi standar yaitu kurang dari $5 \%$.

\subsection{Perancangan Kapasitor Bank}

Faktor daya yang bagus adalah factor daya yang mendekati 1 agar mengurangi kerugian daya akibat factor daya yang buruk yang dapat mengakibatkan naiknya biaya listrik, maka harus dilakukan perbaikan factor daya sebagai berikut:

Daya Semu $(\mathrm{S})=119375$ VA

Cos $\phi$ awal $=0,85$

Daya Aktif $(\mathrm{P})=\mathrm{S} \times \operatorname{Cos} \phi=119375 \times 0,85=101469 \mathrm{~W}$

Daya Reaktif $(\mathrm{Q})=\sqrt{S^{2}-P^{2}}$

$$
=\sqrt{119375^{2}-101469^{2}}=62885 \mathrm{VAR}
$$

Cos $\phi$ yang diinginkan $=0,95$

Daya Semu $1(\mathrm{~S} 1)=\frac{P}{\operatorname{Cos} \phi \text { yang diingginkan }}$

$$
=\frac{101469}{0,95}=106809 \mathrm{VA}
$$

Daya Reaktif $1(\mathrm{Q} 1)=\sqrt{S 1^{2}-P^{2}}$

$$
=\sqrt{106809^{2}-101469^{2}}=33351 \mathrm{VAR}
$$


Kapasitas Kapasitor Bank = Q - Q1

$$
=62885-33351=29533 \mathrm{VAR}
$$

Kapasitor Bank yang digunakan $=30 \mathrm{KVAR}$

Nilai kapasitor bank yang dipasang untuk memperbaiki dan mencapai factor daya yang diinginkan adalah 30 KVAR.

\subsection{Perencanaan Transformator dan Genset}

Trafo dan Genset difungsikan sebagai penyuplai daya untuk gedung Askrindo Bogor. Untuk menentukan kapasitas trafo dan genset adalah sebagai berikut :

a. Beban normal maksimum (S) setelah ditambahkan kapasitor bank $=106809 \mathrm{VA}$

b. Kapasitas minimal trafo dan genset $=106809 \mathrm{VA}+15 \%=122830 \mathrm{VA}$

c. Kapasitas daya trafo PLN yang dijual oleh PLN (berdasarkan brosur) $=131 \mathrm{KVA}$

d. Kapasitas genset yang digunakan (berdasarkan brosur) $=250 \mathrm{KVA}$

\section{KESIMPULAN}

Dari penelitian yang telah dilakukan, didapatkan beberapa kesimpulan sebagai berikut :

a. Berdasarkan perhitungan total kebutuhan beban pada gedung utama, didapatkan rincian sebagai berikut:

1) Beban penerangan : 11.194 watt

2) Beban stop kontak : 8.140 watt

3) Beban AC dan fan : 75.906 watt

b. Dengan menggunakan factor kebutuhan $90 \%$ dan factor diversitas 1,1 maka didapatkan kebutuhan beban maksimum panel MDP gedung utama sebesar 77924 watt

c. Total beban panel LVMDP Gedung askrindo adalah 119375 VA sehingga menggunakan kabel feeder NYFGbY 4 x $95 \mathrm{~mm}^{2}$ dan pengaman utama yaitu MCCB 200 A 4 pole

d. Faktor daya awal diasumsikan 0,85 dan faktor daya yang diinginkan adalah 0,95 maka dipasang kapasitor bank sebesar 30 KVAR untuk menghasilkan nilai faktor daya yang diinginkan.

e. Kapasitas kapasitas daya trafo yang dipasang sesuai dengan ketentuan PLN adalah 131 kVA dan kapasitas genset yang dipasang sesuai dengan brosur dan dengan pertimbangan beban emergensi tambahan seperti suatu acara berskala besar maka dipilih genset dengan kapasitas $250 \mathrm{kVA}$

f. Nilai drop voltage dari trafo ke panel SDP kolam renang dengan panjang kabel $200 \mathrm{~m}$ dengan menggunakan perhitungan adalah $2,438 \%$, sedangkan dengan menggunakan simulasi etap adalah 4,65\%. Kedua nilai tersebut memiliki selisih yang cukup signifikan tetapi masih dibawah batas maksimal ketentuan drop voltage sesuai PUIL 2000 yaitu 5\%.

\section{DAFTAR PUSTAKA}

[1] Andersen.(2018).Penataan dan Pengembangan Instalasi Listrik Fakultas Teknik Unsrat 2017. Jurnal Teknik Elektro,7(3): 207-218.

[2] Valenti,saidila.(2012).Perancangan Instalasi Listrik Gedung Clubhouse di Dago Bandung.Skripsi.Universitas Pendidikan Indonesia.

[3] Hasanah,Nur.(2017).Pengukuran Iluminasi penerangan Lampu FL Pada Ruang Perkuliahan.Jurnal Sains dan Teknologi.7(2):1-7.

[4] Rahma,Sielvya.(2018).Analisis Intensitas Konsumsi Energi RS Medirossa Cikarang.Journal of Electrical and Electronics Engineering, 2(1): 20-3.

[5] Fitriana,Saghifa.(2019).Analisa menentukan rekomendasi penyejuk udara yang tepat menggunakan metode moora .Jurnal Evolusi, 7(1): 89-95.

[6] Januar,Akbar.(2017).Studi Evaluasi Perencanaan Kebutuhan Daya Pada Instalasi Listrik Di Gedung Harco Glodok Jakarta. Universitas Pakuan Bogor.

[7] Sugianto,Abdul Mu'is.(2017).Perencanaan Sistem Distribusi Listrik Pelaksanaan Proyek Apartemen.Sinusoida,19(2): 69-77.

[8] Persyaratan Umum Instalasi Listrik.Sandar Nasional Indonesia.2011. 
